\title{
Rock Physics Models and Seismic Inversion in Reservoir Characterization, "MUN" Onshore Niger Delta Field
}

\author{
James Mwendwa Munyithya',2, Chukwuemeka Ngozi Ehirim³, Tamunonengiyeofori Dagogo³ \\ ${ }^{1}$ The World Bank, ACE-CEFOR, Uniport Post Office, Delta Park, Port Harcourt, Nigeria \\ ${ }^{2}$ Physics Department, JKUAT, Nairobi, Kenya \\ ${ }^{3}$ Physics Department, UNIPORT, Choba, Port Harcourt, Nigeria \\ Email: jmmunyithya@jkuat.ac.ke, ehirimcn@yahoo.com,nengi.dagogo@uniport.edu.ng
}

How to cite this paper: Munyithya, J.M., Ehirim, C.N. and Dagogo, T. (2019) Rock Physics Models and Seismic Inversion in Reservoir Characterization, "MUN" Onshore Niger Delta Field. International Journal of Geosciences, 10, 981-994.

https://doi.org/10.4236/ijg.2019.1011056

Received: September 26, 2019

Accepted: November 19, 2019

Published: November 22, 2019

Copyright $\odot 2019$ by author(s) and Scientific Research Publishing Inc. This work is licensed under the Creative Commons Attribution International License (CC BY 4.0).

http://creativecommons.org/licenses/by/4.0/

\begin{abstract}
Rock Physics Modelling and Seismic Inversion were carried out in an Onshore Niger Delta Field for the purpose of characterizing a hydrocarbon reservoir. The aim of the study was to integrate rock physics models and seismic inversion to improve the characterization of a selected reservoir using well-log and 3D seismic data sets. Seven reservoir sands were delineated using suite of logs from three wells. In this study, the sand 4 reservoir was selected for analysis. The result of petrophysical evaluation shows that the sand 4 reservoir is relatively thick $(62 \mathrm{ft})$ with low water saturation $(0.33)$, shale volume (0.11) and high porosity (0.32). These results indicate reservoir of good quality and producibility. Cross-plot of property pairs (acoustic impedance $\left(I_{p}\right)$ vs. lambda-rho $(\lambda \rho)$ and mu-rho $(\mu \rho)$ vs. lambda-rho $(\lambda \rho)$ color-coded with reservoir properties reveals three distinct probable zones: hydrocarbon sand, brine sand and shale. Results show that low $I_{p}, \lambda \rho$ and $\mu \rho$ associated with hydrocarbon charged sands correspond to low $S_{w}$ and $V_{s h}$ and high $\phi$. The integration of rock physics models and inverted rock attributes effectively delineated and improved understanding of already producing reservoirs, as well as other hydrocarbon charged sands of low $\mathrm{S}_{\mathrm{w}}, \mathrm{V}_{\mathrm{sh}}$, and high $\phi$ to the east of existing well locations, which indicate possible by-passed hydrocarbon pays. The results of this work can assist in forecasting hydrocarbon prospectivity and lessen chances of drilling dry holes in MUN onshore Niger delta field.
\end{abstract}

\section{Keywords}

Seismic Inversion, Rock Physics Models, Reservoir Properties, Rock Attributes, Hydrocarbon Sands 


\section{Introduction}

The knowledge of elastic rock properties in reservoir characterization is important as they closely relate to quantitative reservoir properties. Rock physics plays an important role in the hydrocarbon prospecting as a bridge between these elastic parameters and reservoir properties, providing the basic relationships between reservoir seismic response and lithology, pore fluid, pressure, temperature and porosity of the reservoir [1]. The elastic parameters being used over time in reservoir studies include seismic velocity, density, impedance, $\mathrm{Vp} / \mathrm{Vs}$ ratio, Poisson's ratio, lambda-rho and mu-rho, whose sensitivity to reservoir properties depends on the intrinsic quality of the seismic data and reservoir character.

Apart from characterization, the changes in reservoir properties caused by production can be monitored using these elastic rock parameters. Withdraw of mass (hydrocarbon) is expected to result in compaction and pressure changes in the reservoir. [2] demonstrated that changes in the rock derived attributes (density, lambda-rho, impedance) indicated change in reservoir properties of a Niger Delta Field (pore saturation and pressure). Similarly, ground subsidence due to hydrocarbon extraction was inferred from evaluating density, lambda-rho and acoustic impedance changes [3]. Both observations show that elastic rock properties can be used in exploration and production stages to understand the physical behavior of the reservoir.

Rock physics analysis involves cross plotting elastic parameters with reservoir properties and uses rock physics models to enable characterize reservoir by differentiating lithology and fluid or distinguishing sand from shale [4]. The elastic properties inverted from seismic data can be efficiently interpreted in conjunction with a rock physics model, which in turn can be used to predict lithology and fluid content reliably and quantitatively across the field.

The goal of seismic inversion is to predict rock and fluid properties, for reservoir characterization from seismic data. In seismic inversion, the seismic data is converted into elastic layer properties such as $\mathrm{P}$ - and S-impedances, density, $\mathrm{P}$ and S-wave velocities, and all the related seismic attributes [5] [6]. Generally, elastic parameters with lithological sensitivity such as S-wave impedance, $\mathrm{P}$-wave impedance, density, shear modulus, and bulk modulus are routinely employed to distinguish between shale and sandstone, good and poor reservoir. On the other hand, fluid sensitive parameters such as elastic wave velocity, poisson ratio, Lamé constants, and the ratio of P-and-S-wave velocity are used to discriminate water, oil and gas in hydrocarbon reservoirs [7] [8].

With the application of rock physics analysis and seismic inversion in exploration and appraisal efforts, the efficiency of reservoir prediction and hydrocarbon detection has increased greatly [9] [10]. This is hinged on established relations between the elastic and reservoir properties at the well locations from rock physics models. Such established relations at the well locations can then be used to interpret reservoir properties away from well control points using inverted 
elastic properties.

This study was carried out in the coastal swamp depobelt of the Niger Delta (Figure 1). The Niger Delta forms one of the world's largest hydrocarbon provinces and it is situated on the Gulf of Guinea and extends through the Niger Delta provinces [11]. It covers an area within longitude $4^{\circ} \mathrm{E}-9^{\circ} \mathrm{E}$ and latitudes $4^{\circ} \mathrm{N}-9^{\circ} \mathrm{N}$. The swamp depobelt is characterized by rain forest and mangrove vegetations, average elevation with landscape incised by numerous brackish rivulets and creeks, high torrential rainfall and relative humidity.

The present study is aimed at integrating rock physics models in the interpretation of inverted seismic data for reservoir property characterization in Niger Delta "MUN" Onshore field.

\section{Geology of the Study Area}

The Niger Delta is composed of regressive clastic sequence of tertiary age [12]. The Niger Delta has prograded southwards overtime, forming depobelts (Figure 2) that represent the most active portion of the delta at each stage of its development [13]. These depobelts form one of the largest regressive deltas in the world with an area of about $300,000 \mathrm{~km}^{2}$, a sediment volume of about 500,000 $\mathrm{m}^{3}$ and a sediment thickness of over $10 \mathrm{~km}$ in the basin depocenter [14] [15]. The Tertiary section of the Niger Delta is divided into three formations: Benin, Agbada (the reservoir rock) and Akata (the source rock and reservoir in deep offshore) Formations. The Akata-Agbada formations are the known tertiary Niger Delta petroleum system [16].

Initially, continental divergence of African and South American plates and at later time gravity tectonics have caused deformation in the Akata and overlying Agbada Formation, in Niger Delta resulting in complex stratigraphic and faulting systems and anticlinal structures, fit for hydrocarbon traps and conduit (Figure 3).

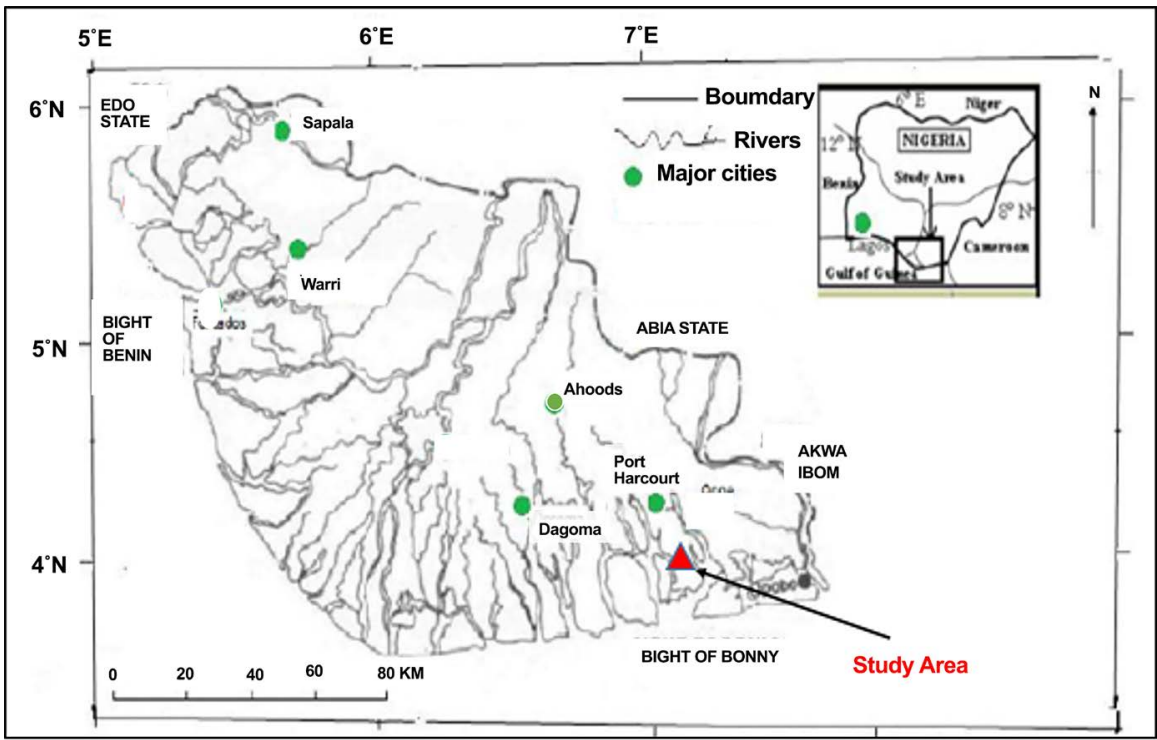

Figure 1. Location map of the study area [17]. 


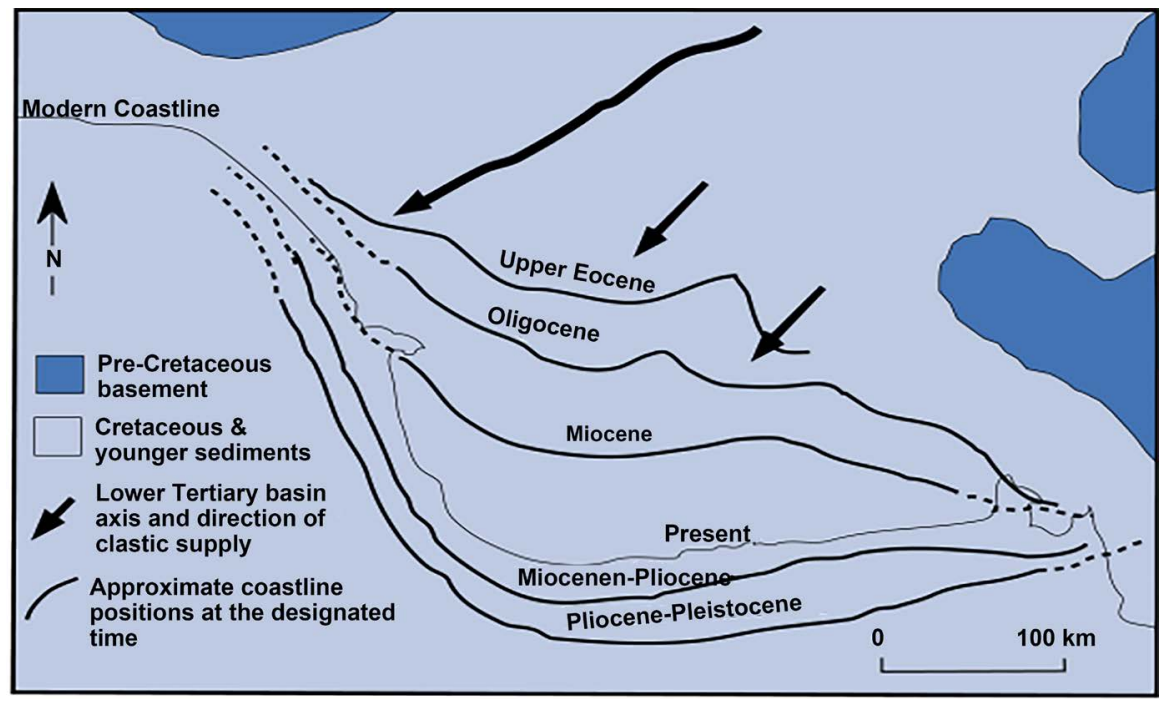

Figure 2. Depobelts and direction of sediment deposition [16].

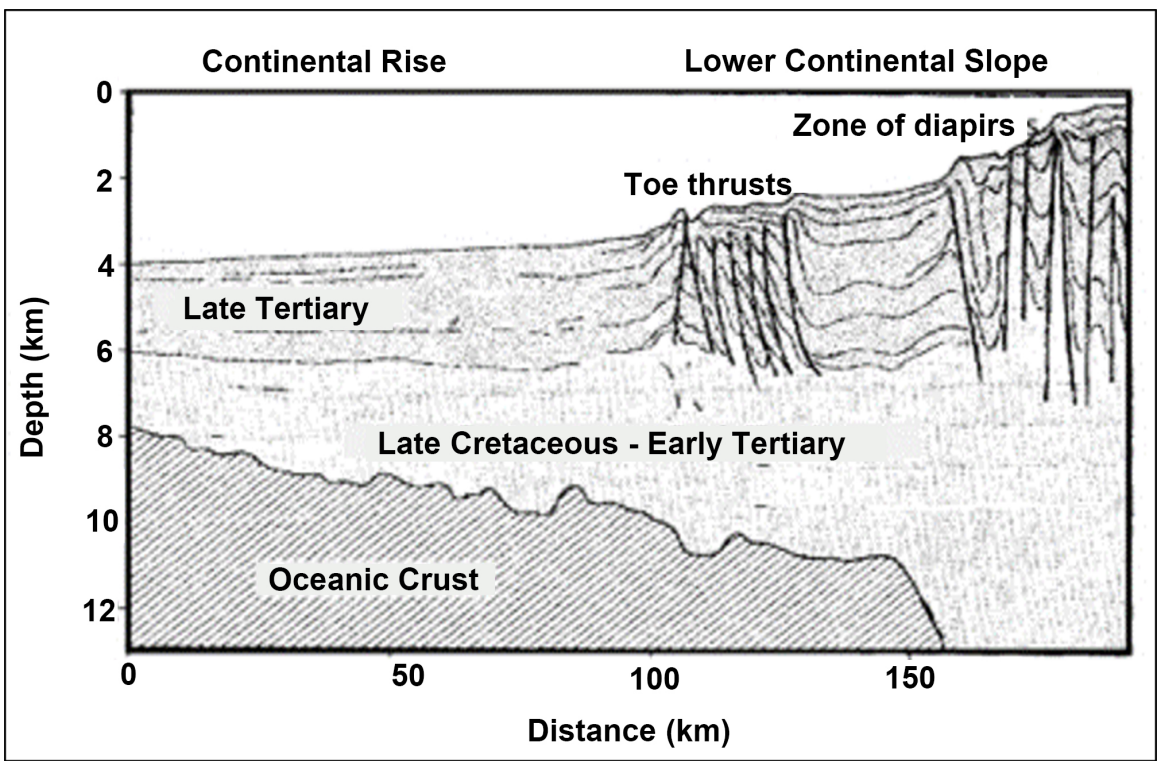

Figure 3. Gravity tectonics of Niger Delta Continental Margin [13].

\section{Method of Study}

The data used for this study consist of well logs from three wells (MUN 14, 15 and 16), which comprise gamma (GR), resistivity (RT), neutron (NPHI) and density (RHOB) logs, and post-stack time migrated seismic data from "MUN" onshore Niger Delta field. The well positions and seismic inline and crosslines in "MUN" field are shown in the base map of the study (Figure 4). The methodology involved three parts: petrophysical evaluation, well-based rock physics cross-plots and models and inversion of elastic properties from the seismic data.

The reservoirs of interest were delineated using a combination of gamma and resistivity logs. Gamma ray log was used to discriminate lithologies whereas resistivity $\log$ was used to characterize fluid contents of the delineated reservoir. 


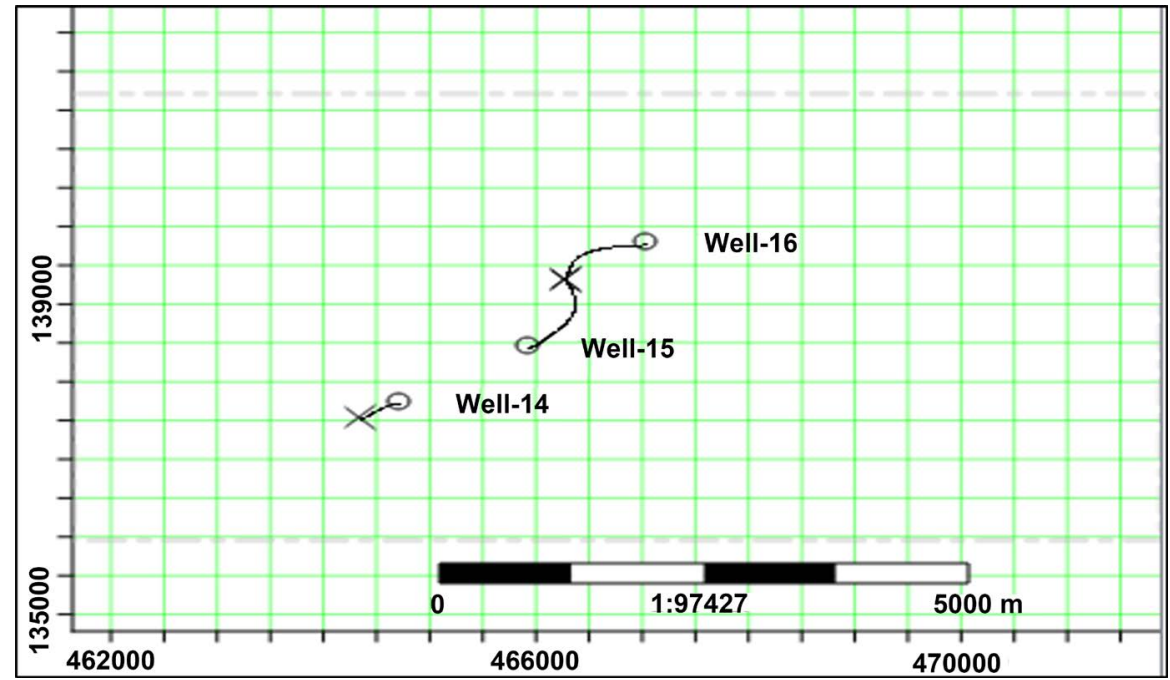

Figure 4. Base Map showing well position in the field.

Seven reservoirs were delineated from well 14, 15 and 16. Sand 4 reservoir was used for the present study. Quantitative analysis involved modelling of Pseudo-logs of elastic rock attributes and estimation of petrophysical parameters (shale volume $\left(\mathrm{V}_{\text {sh }}\right)$, porosity $(\phi)$ and water saturation $\left(\mathrm{S}_{\mathrm{w}}\right)$ ) from well logs using appropriate basic rock physics [18] [19] and empirical petrophysical relations (Figure 5(a), Figure 5(b)).

Well-based rock attribute properties were cross plotted, color-coded with density and reservoir properties in 3-D cross plot space with the aim of identifying the most appropriate attribute property that better discriminates lithology and pore fluid and established relations between these attributes and reservoir properties.

Well correlation and seismic to well tie were done to facilitate horizon mapping on the seismic data section. Subsequently, three horizons were mapped out (HA, H4 and H7), guided by reservoir markers in well logs. The seismic data set was inverted into an impedance volume using a model-based inversion scheme, which involves generating low frequency model, guided by well-logs and interpreted horizons. Finally, other elastic attribute properties such as lambda-rho and mu-rho were extracted from the impedance volume along $\mathrm{H} 4$ seismic horizon and used for field wide characterization of the reservoir.

\section{Results Presentation}

The wells were analyzed for lithology and fluid using gamma ray and resistivity logs. Shale lithologies were delineated by high gamma ray (GR) value with very low resistivity (RT). Hydrocarbon sands, on the other hand, were delineated by low GR values with high RT, while brine sand has low gamma ray with low RT. The wells display a shale/sand/shale sequence which is characteristic of the Niger delta formation. Results of quantitative analysis of well logs show that sand 4 hydrocarbon reservoir is a moderately thick reservoir, having low volume of 


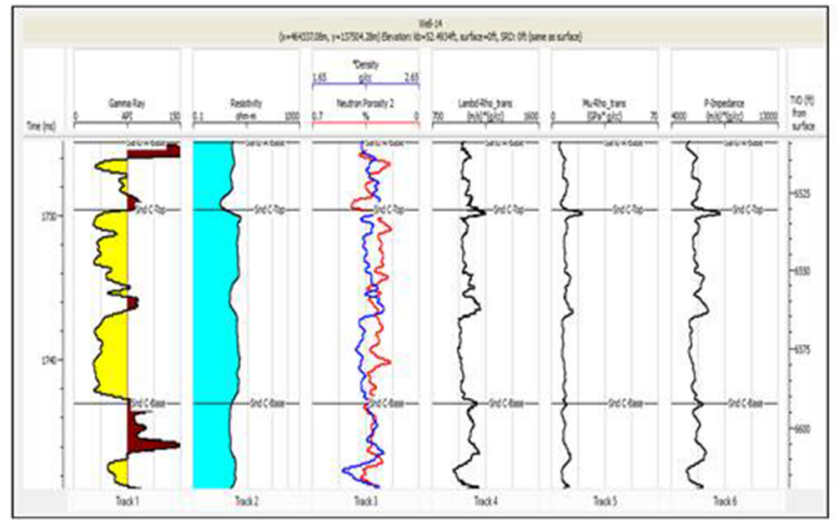

(a) Rock Attributes

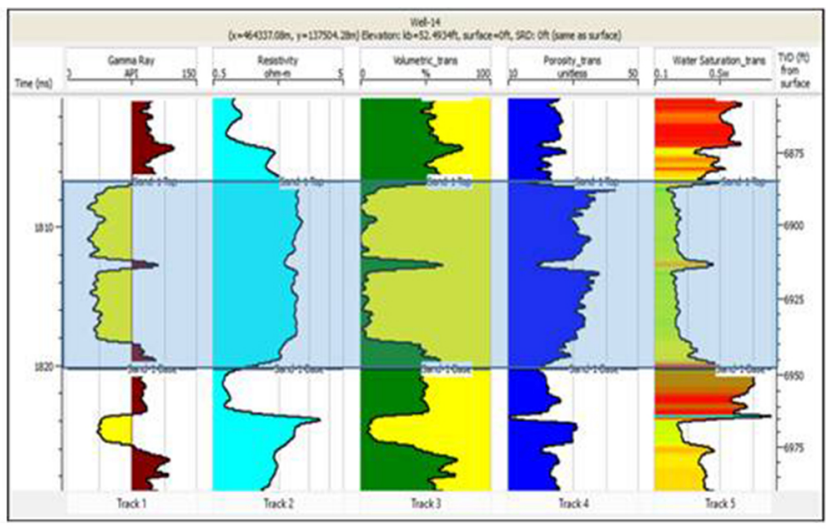

(b) Reservoir properties

Figure 5. (a), (b). Modelled Pseudo-logs of elastic and reservoir properties for well 14.

shale and water saturation and high porosity. The estimated average reservoir properties are shown in Table 1 for the three wells.

The high porosity, low shale volume and water saturation indicate good reservoir quality and reflects probably coarse-grained sandstone reservoirs with minimal cementation.

Several rock property pairs ( $\mathrm{I}_{\mathrm{p}}$ vs. $\sigma, \mathrm{V}_{\mathrm{p}} / \mathrm{V}_{\mathrm{s}}$ vs. $\mu \rho ; \mu \rho$ vs. $\lambda \rho$; $\mathrm{I}_{\mathrm{p}}$ vs. $\lambda \rho$ etc.) were cross plotted and the best property pairs with heightened sensitivity to fluid and lithology were selected for the present analysis. The results of cross plot of $I_{p}$ versus $\lambda \rho$ and $\mu \rho$ versus $\lambda \rho$, color-coded with density, show that data clusters are separated into three distinct zones interpreted to be hydrocarbon sand, brine sand and shale, respectively (Figure 6(a), Figure 6(b)). From the cross-plots hydrocarbon charged sands have low density, $\mathrm{I}_{\mathrm{p}}, \mu \rho$ and $\lambda \rho$, brine sands have low $\mathrm{I}_{\mathrm{p}}$ and $\mu \rho$, and moderate $\lambda \rho$, while shale has all high density, $\mathrm{I}_{\mathrm{p}}, \mu \rho$ and $\lambda \rho$.

The result of cross-plot of $\mu \rho$ versus $\lambda \rho$, color coded with reservoir properties $\mathrm{S}_{\mathrm{w}}, \mathrm{V}_{\mathrm{sh}}$ and $\phi$, respectively (Figures $7(\mathrm{a})-(\mathrm{c})$ ), shows that hydrocarbon saturated sand zones characterized by low $\mu \rho$ and $\lambda \rho$ attribute values, also have low $\mathrm{S}_{\mathrm{w}}$ and $\mathrm{V}_{\mathrm{sh}}$ and high $\phi$ compared to brine sands and shale zones, respectively.

The result of cross plot of $\mathrm{I}_{\mathrm{p}}$ versus $\lambda \rho$, color coded with reservoir properties $S_{w}, V_{s h}$ and $\phi$ shows that hydrocarbon saturated sands were delineated by low $I_{p}$ and $\lambda \rho$ attribute values, corresponding to high reservoir $\phi$, low $\mathrm{V}_{\text {sh }}$ and $\mathrm{S}_{\mathrm{w}}$ (Figures 8(a)-(c)).

The results of the rock physics models established empirical relationships between the elastic and reservoir properties. These established relationships will greatly assist in the interpretation of the seismic data and characterization of sand 4 reservoir across MUN onshore field.

The inverted acoustic impedance section is shown in Figure 9, with the wells and seismic horizons inserted. Result shows a general increase in acoustic impedance with depth, suggesting increasing compaction of the underlying sediments due to the weight of the overburden. Low acoustic impedances were delineated along the two seismic horizons (HA and $\mathrm{H} 4$ ), indicating hydrocarbon 
Table 1. Summary of the petrophysical properties of Sand 4 Reservoir.

\begin{tabular}{ccccccc}
\hline Well & $\begin{array}{c}\text { Top } \\
(\mathrm{ft})\end{array}$ & $\begin{array}{c}\text { Bottom } \\
(\mathrm{ft})\end{array}$ & $\begin{array}{c}\text { Thickness } \\
(\mathrm{ft})\end{array}$ & $\begin{array}{c}\mathrm{V}_{\text {shale }} \\
(\mathrm{frac})\end{array}$ & $\begin{array}{c}\varnothing \\
(\mathrm{frac})\end{array}$ & $\begin{array}{c}\mathrm{S}_{\mathrm{w}} \\
(\mathrm{frac})\end{array}$ \\
\hline MUN-14 & 7909 & 7961 & 52 & 0.11 & 0.30 & 0.39 \\
MUN-15 & 7884 & 7950 & 66 & 0.07 & 0.34 & 0.26 \\
MUN-16 & 7844 & 7913 & 69 & 0.14 & 0.33 & 0.34 \\
& Average & & 62 & 0.11 & $\mathbf{0 . 3 2}$ & $\mathbf{0 . 3 3}$ \\
\hline
\end{tabular}

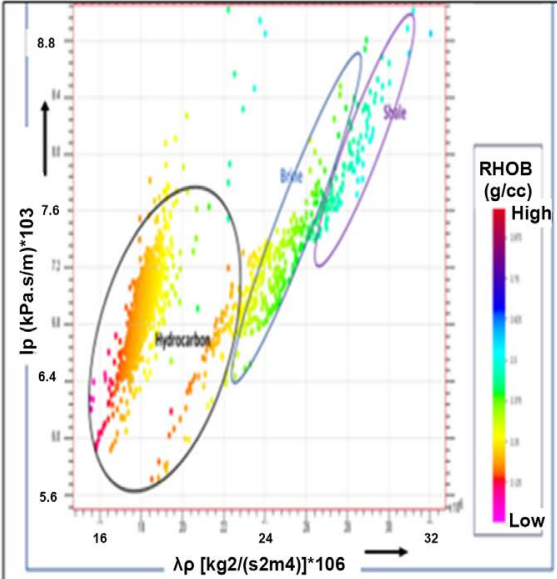

(a) Acoustic Impedance vs Lambda-Rho

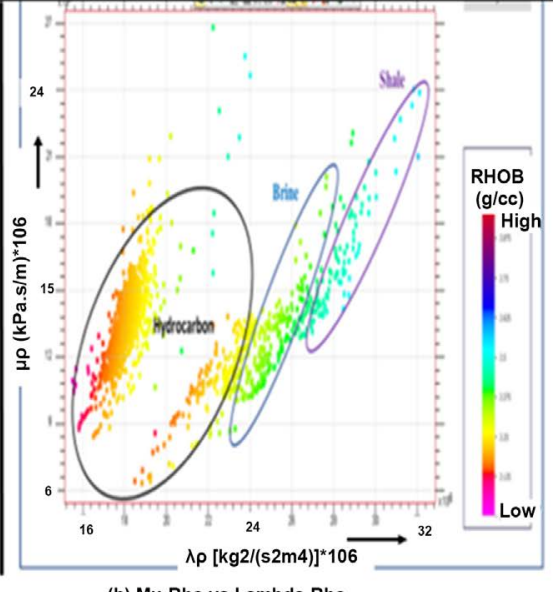

(b) Mu-Rho vs Lambda-Rho

Figure 6. (a) (b). Cross-plots of rock attributes properties for sand 4 reservoir, color-coded with density.

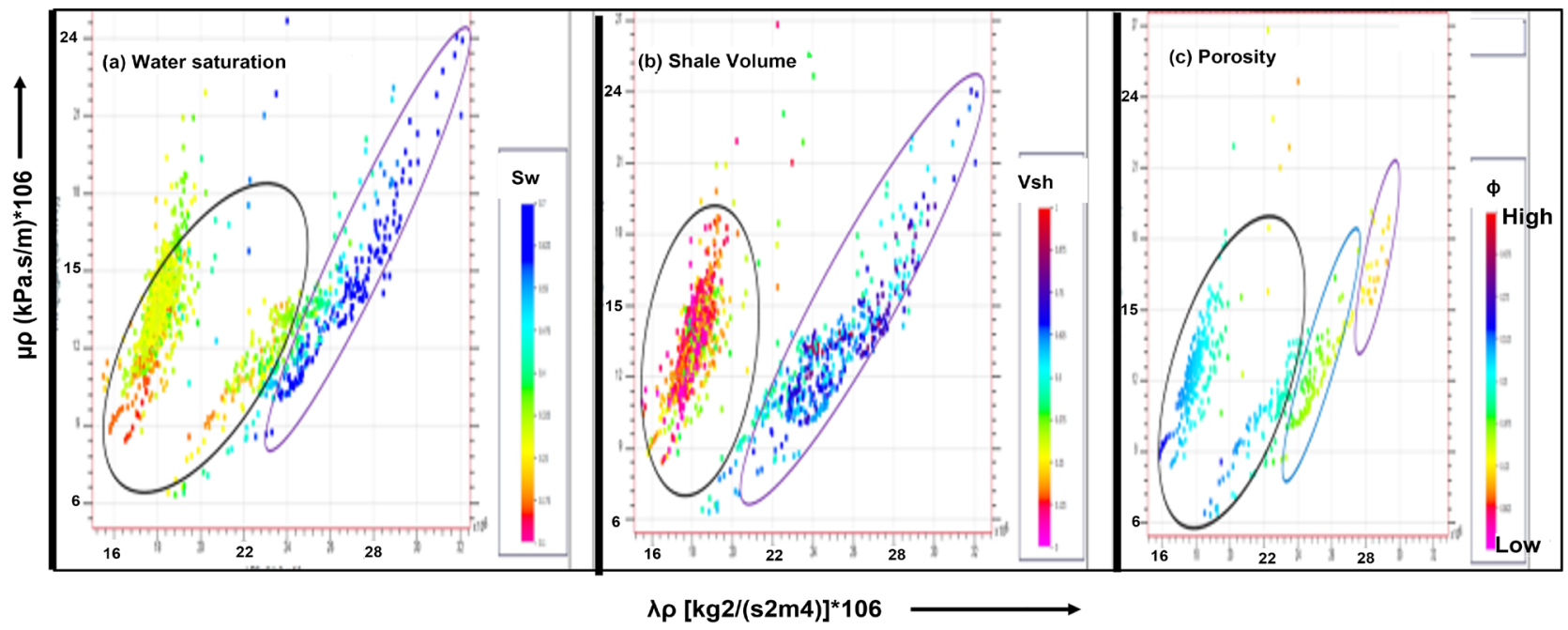

Figure 7. (a) (b) (c). Cross-plots of Mu-Rho $(\mu \rho)$ versus Lambda-Rho $(\lambda \rho)$, color coded with water saturation, shale volume and porosity, respectively.

saturated sands. The structural outlay of these sands ensures reservoir continuity across the field.

The acoustic impedance horizon slice along $\mathrm{H} 4$ seismic horizon shows that the producing wells lie in moderate impedance regions (Figure 10). A low impedance 


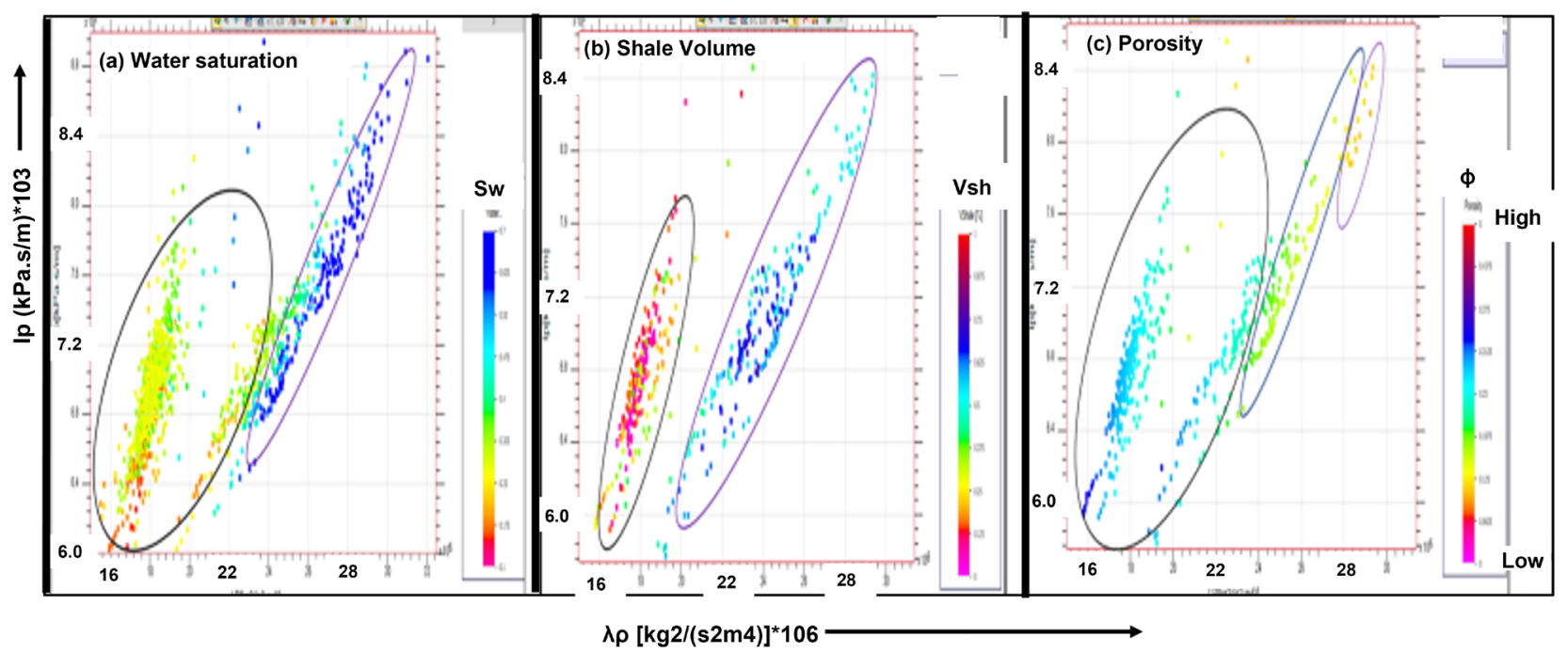

Figure 8. (a) (b) (c). Cross-plots of acoustic impedance $\left(\mathrm{I}_{\mathrm{p}}\right)$ versus Lambda-Rho $(\lambda \rho)$, color coded with water saturation, shale volume and porosity, respectively.

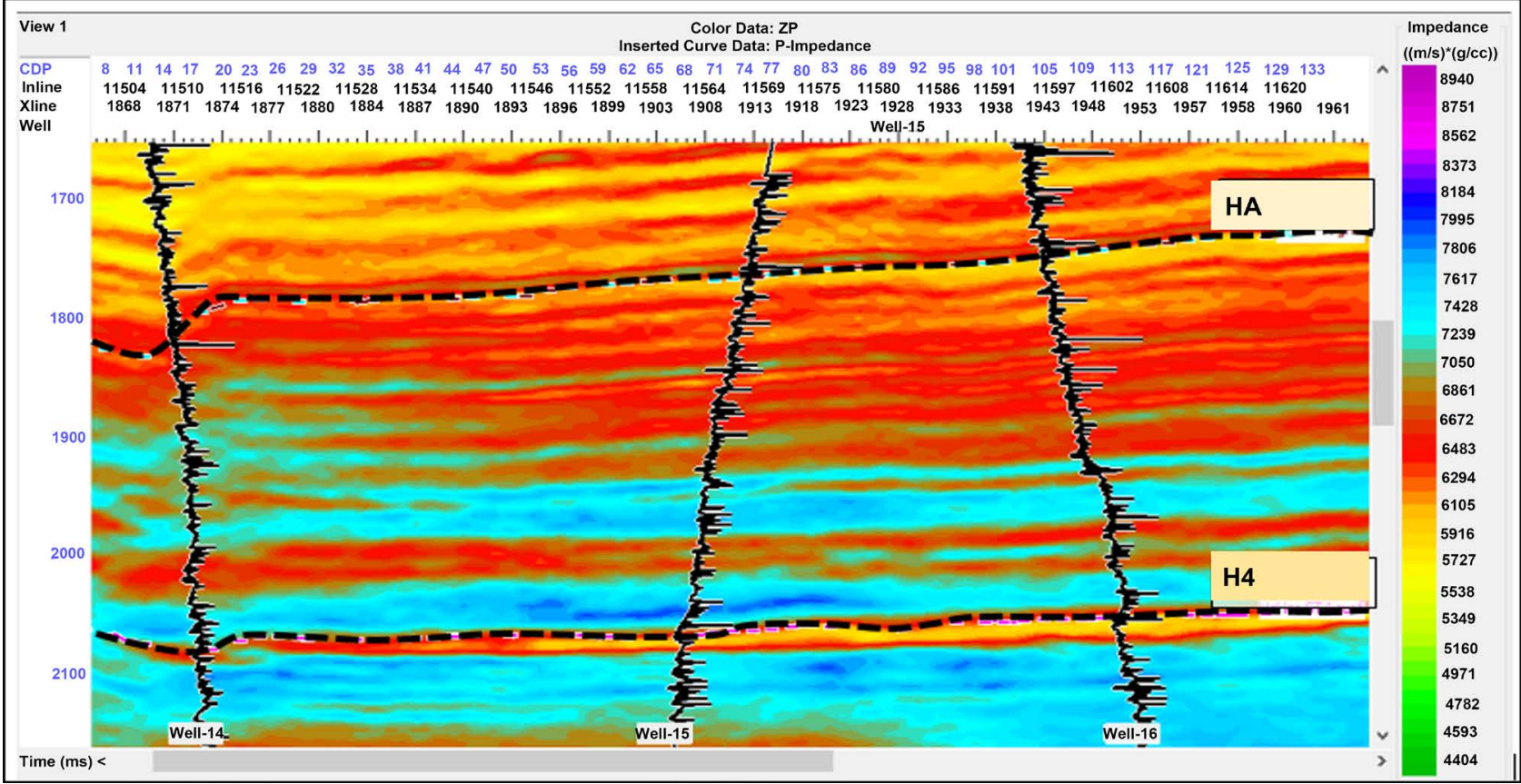

Figure 9. Cross section of acoustic impedance (Ip).

channel-like structure is delineated to the north and east of the producing wells. These low to moderate impedance zones are associated with hydrocarbon charged sands in the field.

The lambda-rho section exhibits gradual increase in lambda-rho with depth (Figure 11). Result shows that $\mathrm{H} 4$ has relatively low lambda rho values, suggesting compaction with depth and increased saturation along the seismic horizon.

The lambda-rho horizon slices along H4 seismic horizon show that the wells lie in moderate lambda-rho zones in the field (Figure 12). An elongated low $\lambda \rho$ 


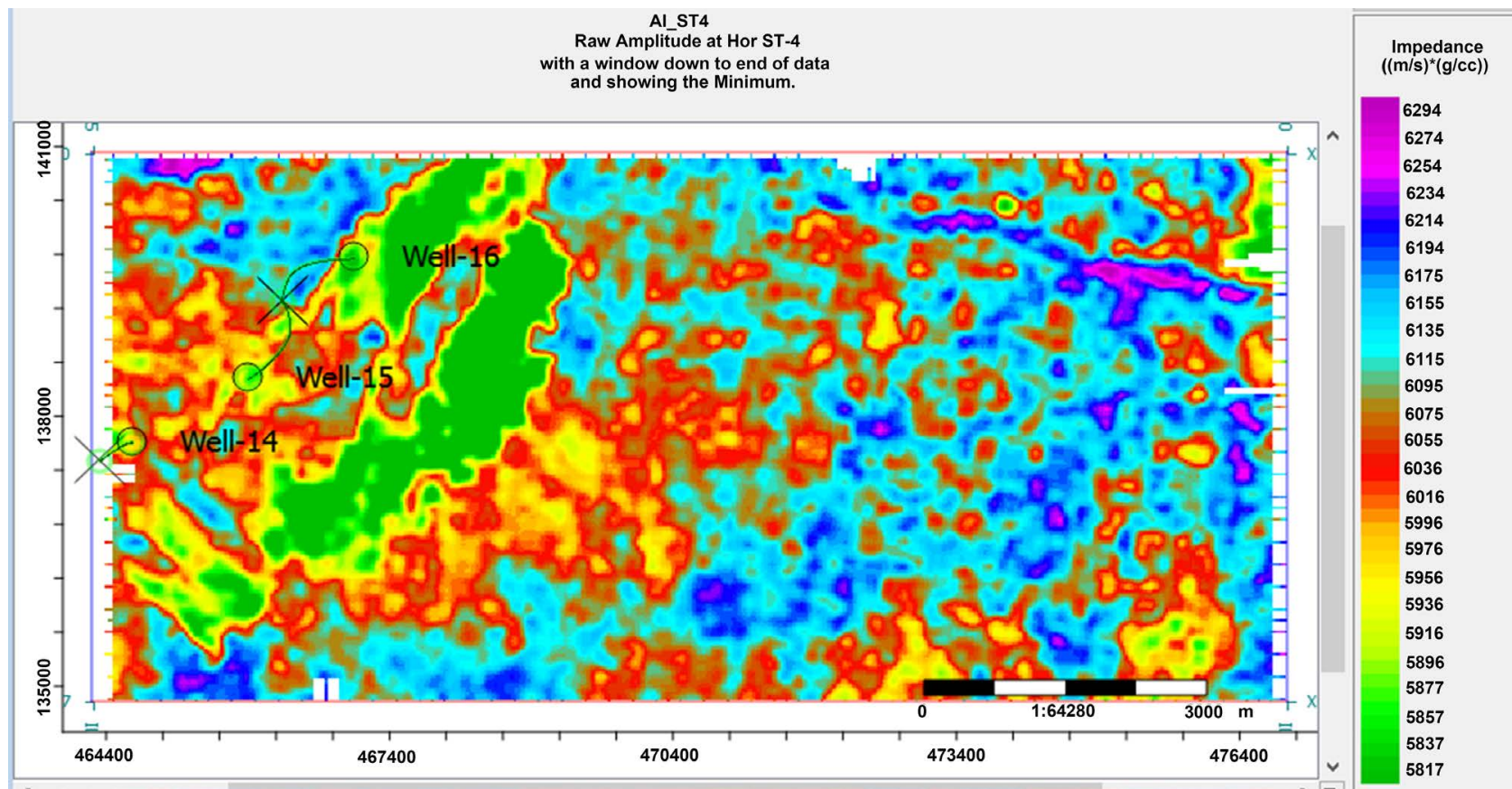

Figure 10. Acoustic impedance horizon map for H4.

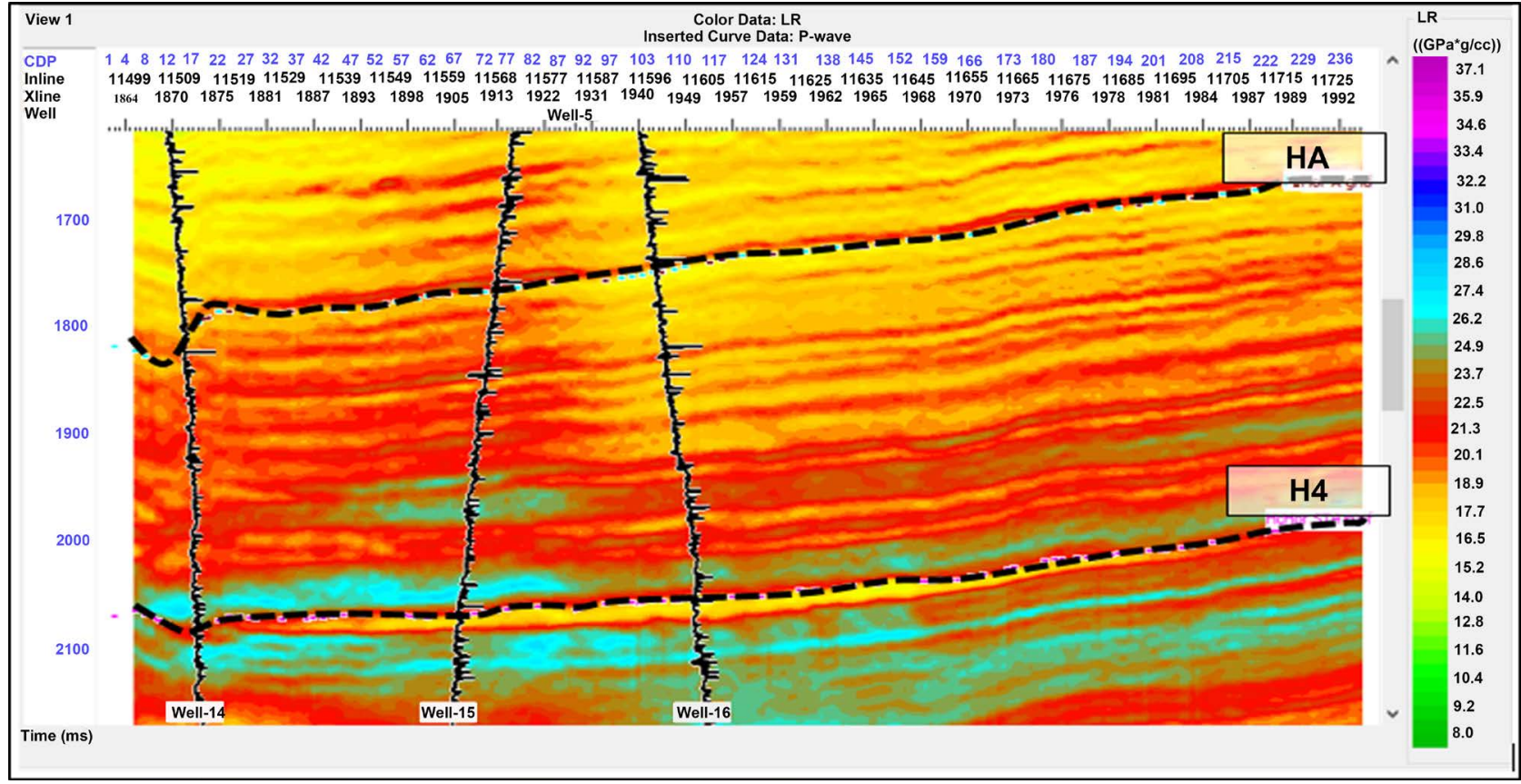

Figure 11. Cross section of lambda-rho $(\lambda \rho)$.

channel-like structure were delineated east to west of the wells, respectively, suggesting probable hydrocarbon charged sands. The elongated low $\mathrm{I}_{\mathrm{p}}$ zone north of the wells becomes diminished in the $\lambda \rho$ horizon map indicating the limitations of $\mathrm{I}_{\mathrm{p}}$ in delineating fluid-filled lithologies compared to the $\lambda \rho$ attribute.

The mu-rho section shows increasing mu-rho with depth (Figure 13). Result shows that $\mathrm{H} 4$ has relatively lower mu-rho values than $\mathrm{HA}$. This could be 


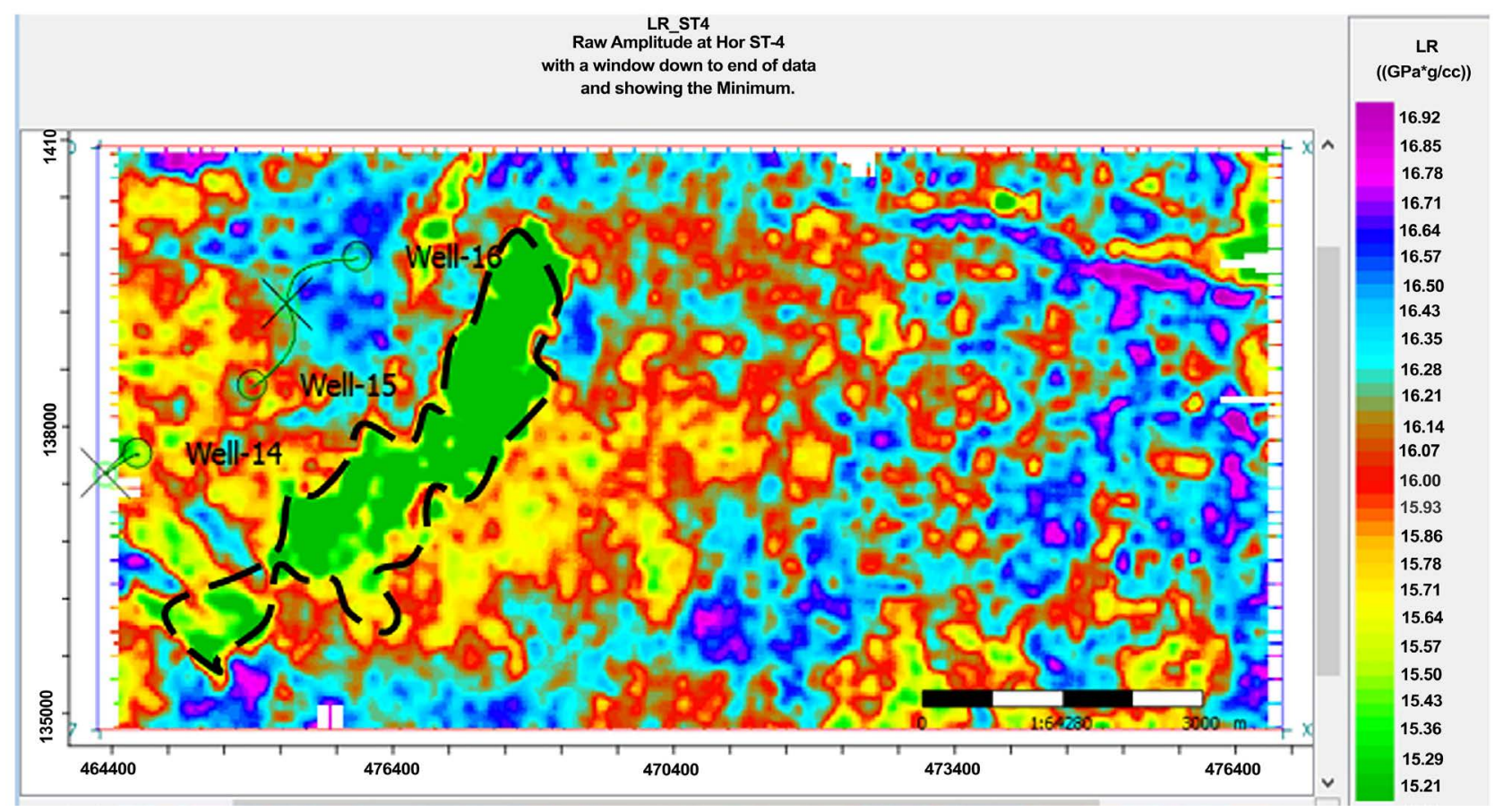

Figure 12. Lambda-rho $(\lambda \rho)$ horizon map for H4.

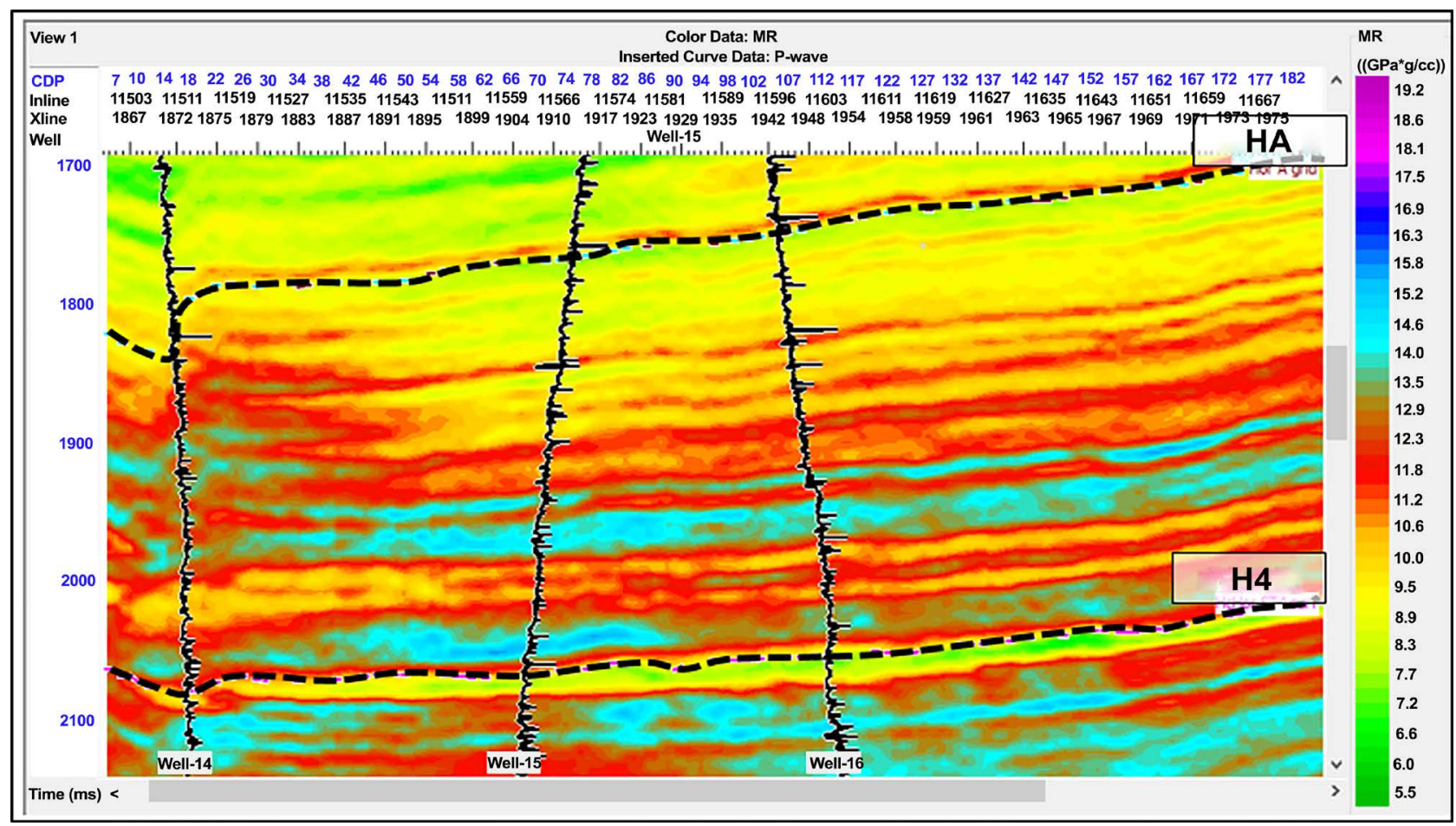

Figure 13. Cross section of $\mathrm{Mu}-$ rho $(\mu \rho)$.

indicative of differential layering and consolidation which has resulted in the different $\mu \rho$ responses observed in the two horizons.

Result shows that the producing wells lie in low mu-rho zones (Figure 14). Low to moderate $\mu \rho$ values were delineated east and west of the wells, indicating 


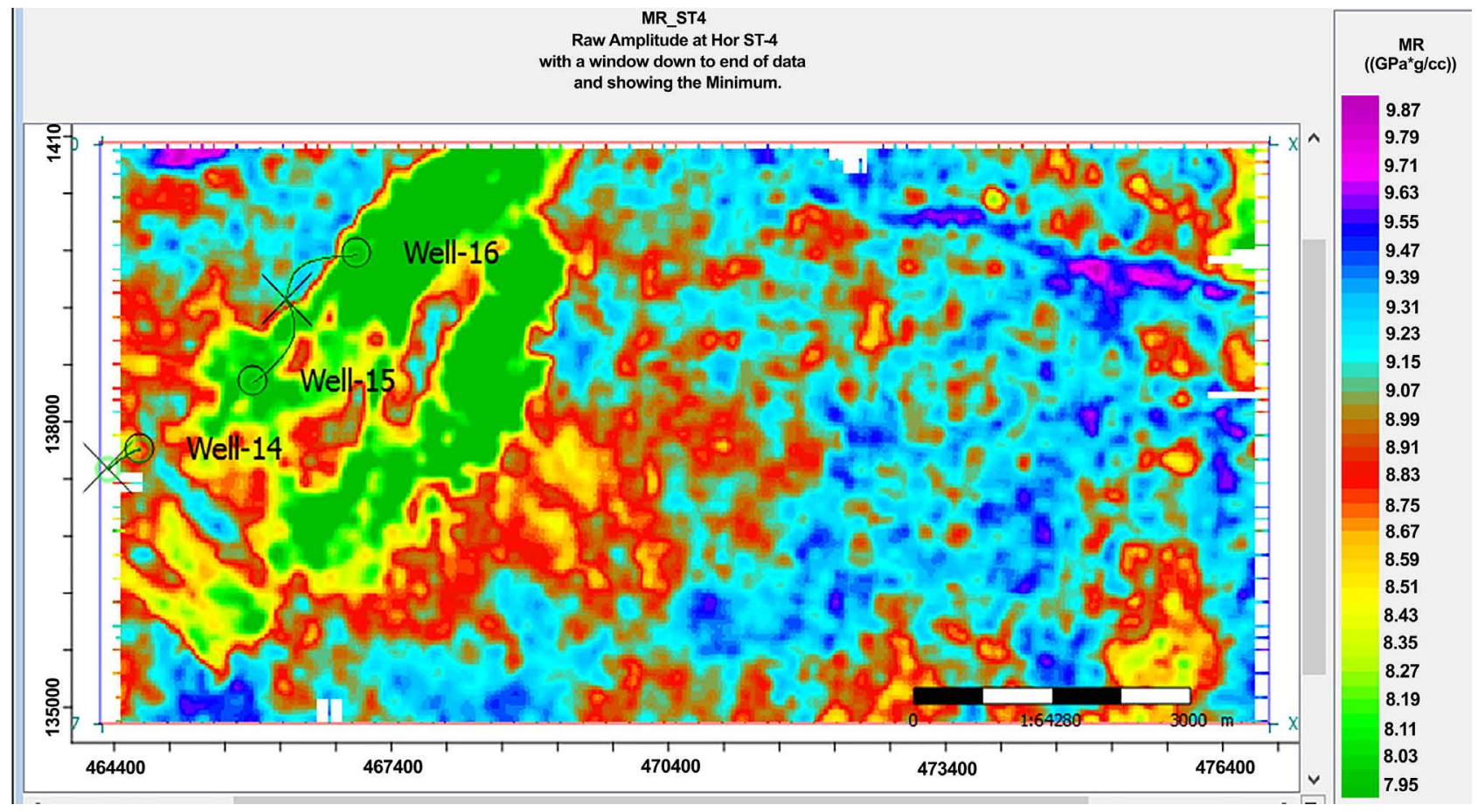

Figure 14. Mu-rho $(\mu \rho)$ Horizon map for H4.

reservoir sands. These are unlikely results for sands are expected to have high $\mu \rho$ values due to their high rigidity compared to shale lithofacies.

\section{Discussions of Results}

Well and 3D seismic data in conjunction with rock physics models, were used in this study to characterize a mapped hydrocarbon reservoir, in terms of lithology, fluid and other relevant reservoir properties. Petrophysical evaluation of the well $\log$ suites from the three wells delineated seven sand reservoirs, however, the sand 4 reservoir was analyzed in this study. The result of petrophysical evaluation shows that the sand 4 reservoir is relatively thick $(62 \mathrm{ft})$, with low water saturation (0.33), shale volume (0.11) and high porosity (0.32), on the average. We note that these average values are stated to give a broad idea of the reservoir quality, while the characterization using the inverted seismic attributes gives details of the expected variations of the properties from point to point. This suggests a sand lithofacies reservoir having high hydrocarbon saturation as is characteristic of most Niger delta fields [20] [21].

Rock attribute properties modelled from well logs were analyzed in 3D cross-plot space with the reservoir properties. Result show that the cross plotted property pairs show heightened sensitivity to reservoir lithology and fluids. Cross-plots of $\mathrm{I}_{\mathrm{p}}$ vs. $\lambda \rho$ and $\mu \rho$ vs. $\lambda \rho$ distinguished the reservoir into hydrocarbon saturated sands, brine sands and shale zones. These well cross-plots show that hydrocarbon sands have low $\mathrm{I}_{\mathrm{p}}, \lambda \rho$ and $\mu \rho$ values. $\mathrm{I}_{\mathrm{p}}$ generally is sensitive to both lithology and fluid, while $\lambda \rho$ is sensitive to fluid and $\mu \rho$ sensitive to rock matrix only. This makes $\mu \rho$ versus $\lambda \rho$ a good discriminator compared to $I_{p}$ ver- 
sus $\lambda \rho$ cross plot. The low $\mu \rho$ values observed for hydrocarbon sands as compared to that for shale, is a characteristic property of Niger delta fields that arises due to the unconsolidation of the reservoir [2] [6] [18].

The attribute property cross plots color coded with reservoir properties show that low $\mathrm{I}_{\mathrm{p}}, \lambda \rho$ and $\mu \rho$ associated with hydrocarbon sands, corresponds to low $\mathrm{S}_{\mathrm{w}}$ and $\mathrm{V}_{\mathrm{sh}}$, and high reservoir $\phi$. Based on these rock physics models and deductions, the inverted seismic attributes along time horizons were used to characterize the reservoir fieldwide.

Results of inverted seismic attributes along $\mathrm{H} 4$ seismic horizon exhibit lateral variations, within and away from the well locations. The wells are located in regions of relatively low $\mathrm{I}_{\mathrm{p}}, \lambda \rho$ and $\mu \rho$. To the east of the wells, there is an elongated channel-like structure with very low $\mathrm{I}_{\mathrm{p}}, \lambda \rho$ and $\mu \rho$ values, interpreted as probable hydrocarbon bearing sands having low $\mathrm{S}_{\mathrm{w}}$ and $\mathrm{V}_{\mathrm{sh}}$ and high values of $\phi$ in line with results of well log-based rock physics models. The rock physics models validate this observation as low $\mathrm{I}_{\mathrm{p}}, \lambda \rho$ and $\mu \rho$ corresponds to hydrocarbon charged sands with high $\phi$ and low Sw and Vsh. Therefore, we have delineated reservoir sands that are probably hydrocarbon charged away from the existing well locations that could be regarded as by-passed pays with characteristic low Sw and Vsh and high $\phi$ which can be investigated for development.

\section{Conclusion}

The petrophysical evaluation of the well data delineated reservoirs, and sand 4 reservoir exhibited good average reservoir characteristics: high $\phi(0.32)$, low $S_{w}$ (0.33), low $\mathrm{V}_{\mathrm{sh}}(0.11)$ and gross thickness of $62 \mathrm{ft}$. Rock Physics modelling and seismic inversion carried out in "MUN" onshore Niger delta field were able to delineate hydrocarbon charged sand zones away from the wells. The integration of rock physics models and inverted rock attributes effectively delineated and improved understanding of already producing reservoirs, as well as other hydrocarbon charged sands of low $S_{w}, V_{s h}$, and high $\phi$ to the east of existing well locations, which indicate possible by-passed hydrocarbon pays. The results of this work can assist in forecasting hydrocarbon prospectivity and lessen chances of drilling dry holes in MUN onshore Niger delta field.

\section{Acknowledgements}

We would like to thank Shell Petroleum Development Company of Nigeria for providing the 3D PSTM data for the study. Our thanks also go to World Bank African Centre of Excellence, Centre for OilField Chemical Research (ACE-CEFOR, University of Port Harcourt), Jomo Kenyatta University of Agriculture and Technology (JKUAT) and RUFORUM for their support.

\section{Conflicts of Interest}

The authors declare no conflicts of interest regarding the publication of this paper. 


\section{References}

[1] Chi, X.G. and Han, D.H. (2009) Lithology and Fluid Differentiation Using a Rock Physics Template. The Leading Edge, 28, 60-65. https://doi.org/10.1190/1.3064147

[2] Dagogo, T., Ehirim, C.N. and Ebeniro, J.O. (2016) Enhanced Prospect Definition Using Well and 4D Seismic Data in a Niger Delta Field. International Journal of Geosciences, 7, 977-990. https://doi.org/10.4236/ijg.2016.78074

[3] Ehirim, C.N. and Dagogo, T. (2016) Subsidence Inferred from a Time Lapse Reservoir Study in a Niger Delta Field, Nigeria. Current Research in Geosciences, 6, 98-106. https://doi.org/10.3844/ajgsp.2016.98.106

[4] Abe, S.J., Olowokere, M.T. and Enikanselu, P.A. (2018) Development of Model for Predicting Elastic Parameters in 'Bright' Field, Niger Delta Using Rock Physics Analysis. NRIAG Journal of Astronomy and Geophysics, 7, 264-278. https://doi.org/10.1016/j.nrjag.2018.05.006

[5] Russell, B.H. (1988) Introduction to Seismic Inversion Methods. https://doi.org/10.1190/1.9781560802303

[6] Ekwe, A.C.; Onuoha, K.M. and Osayande, N. (2012) Fluid and Lithology Discrimination Using Rock Physics Modelling and Lambdamurho Inversion: An Example from Onshore Niger Delta, Nigeria. AAPG International Conference and Exhibition, Milan, Italy.

[7] Hamada, G.M. (2004) Reservoir Fluids Identification Using Vp/Vs Ratio? Oil Gas Science and Technology, 59, 649-654. https://doi.org/10.2516/ogst:2004046

[8] Bello, R., Igwenagu, C.L. and Onifade, Y.S. (2015) Cross Plotting of Rock Properties for Fluid and Lithology Discrimination Using Well Data in a Niger Delta Oil Field. Journal of Applied Sciences and Environmental Management, 19, 536-546.

http://www.bioline.org.br/pdf?ja15068

https://doi.org/10.4314/jasem.v19i3.25

[9] Tian, L., Zhou, D., Lin, G. and Jiang, L. (2010) Reservoir Prediction Using Poisson Impedance in Qinhuangdao, Bohai Sea. SEG Denver 2010 Annual Meeting, 2261-2264. https://doi.org/10.1190/1.3513300

[10] Oyeyemi, K.D., Olowokere, M.T. and Aizebeokhai, A.P. (2018) Hydrocarbon Resource Evaluation Using Combined Petrophysical Analysis and Seismically Derived Reservoir Characterization, Offshore Niger Delta. Journal of Petroleum Exploration and Production Technology, 8, 99-115. https://doi.org/10.1007/s13202-017-0391-6

[11] Klett, T.R., Ahlbrandt, T.S., Schmoker, J.W. and Dolton, J.L. (1978) Ranking of The World's Oil and Gas Provinces by Known Petroleum Volumes. USGS Open-File Report 97-463. https://pubs.usgs.gov/of/1997/ofr-97-463/

[12] Evamy, B.O., Herembourne, J., Kameline, P., Knap, W.A., Molloy, F.A. and Rowlands, P.H. (1978) Hydrocarbon Habitat of Tertiary Niger Delta. American Association of Petroleum Geologists Bulletin, 62, 1-39. https://doi.org/10.1306/C1EA47ED-16C9-11D7-8645000102C1865D

[13] Doust, H. and Omatsola, M. (1990) Divergent and Passive Margin Basins. American Association of Petroleum Geologist Bulletin, 48, 201-238.

[14] Adiela, U.P. and Jayeola, A.O. (2017) Reservoir Studies and Petrophysical Attributes; Case Studies of Cat-1 Reservoir Sands, Onshore, Niger Delta Nigeria. International Journal for Innovative Research in Multidisciplinary Field, 3, 9-14.

[15] Meindinyo, K.O. (2017) Hydrocarbon Production Induced-Faulting in the Niger Delta, Using Time Lapse Seismic.

https://www.academia.edu/35819776/HYDROCARBON_PRODUCTION_INDUC 
ED-FAULTING_IN_THE_NIGER_DELTA_USING_TIME_LAPSE_SEISMIC

[16] Tuttle, M.L.W., Brownfield, M.E. and Charpentier, R.R. (1999) The Niger Delta Petroleum System: Niger Delta Province, Nigeria, Cameroon, and Equatorial Guinea, Africa. Tertiary Niger Delta (Akata-Agbada) Petroleum System (No. 701901) Open-File Report 99-50-H. https://doi.org/10.3133/ofr9950H

[17] Obiekezie, T.N. and Bassey, E.E. (2015) Petrophysical Analysis and Volumetric Estimation of Otu Field, Niger Delta Nigeria, Using 3D Seismic and Well Log Data. Physical Science International Journal, 6, 54-65. https://doi.org/10.9734/PSIJ/2015/15320

[18] Goodway, W., Chen, T. and Downton, J. (1997) Improved AVO fluid detection and lithology discrimination using Lamé petrophysical parameters; $\lambda \rho, \mu \rho \& \lambda / \mu$ fluid stack from $\mathrm{P}$ and $\mathrm{S}$ inversions. 67th Annual International Meeting, SEG, Expanded Abstracts, 183-186. https://doi.org/10.1190/1.1885795

[19] Chopra, S. and Castagna, J. (2014) AVO. Investigation in Geophysics Series No.16. SEG, 55. https://doi.org/10.1190/1.9781560803201

[20] Nwankwo, C.N., Anyanwu, J. and Ugwu, S.A. (2014) Integration of Seismic and Well Log Data for Petrophysical Modeling of Sandstone Hydrocarbon Reservoir in Niger Delta. Scientia Africana, 13, 186-199.

[21] Emujakporue, G.O. (2016) Assessment of Hydrocarbon Potential in Owem Field in Niger Delta, Nigeria. International Journal of Geosciences, 7, 335-344.

https://doi.org/10.4236/ijg.2016.73026 